JPH RECODE Vol. 1 No. 1 (2017)

\title{
RISK MANAGEMENT KESELAMATAN DAN KESEHATAN KERJA PADA ENGINE ROOM KAPAL FERI SELAT MADURA II SURABAYA
}

\author{
Ronggo Yudo Wicaksono* \\ *Program Studi S1 Kesehatan Masyarakat, Fakultas Kesehatan Masyarakat, Universitas Airlangga \\ Email: redsunsholic93@gmail.com
}

\begin{abstract}
Risk Management OHS is an effort to manage Occupatinal Health and Safety (OHS) risk to prevent accidents in a systematic and well structured.The purpose of this research is to do risk management on engine room Ferry Ship Selat Madura II Surabaya.This research is an observational research which is a cross sectional research based on the time of the research. The object of this research was concerned on engine room, with 6 persons as the population of all engine room's crew. Primary data obtained through observation and interview that were analyzed descriptively. The result of this research showed that in engine room there were 25 kind of hazards which 5 hazards are belong to high risk level or unacceptable category, 20 hazards as medium risk level or tolerated, and the rest 5 hazards as low risk level or acceptable category. The effort of control that applied was technically engineering control, administrative and supply of Personal Protective Equipment (PPE). The most effective control was management installation in safety device on machine, with $90 \%$ of the value. Based on assessment residual risk, there were still 6 hazards ofmoderate risk level. The conclusion of this research is, from the total of 25 kinds of hazard in the engine room of Ferry Ship Selat Madura II, $20 \%$ are belong to high risk level or unacceptable hazard, but the controls that applied have 90\% of value, thus $76 \%$ hazard which is categorized as high level risk or unacceptable hazard can be downgraded into acceptable hazard.
\end{abstract}

Keywords: engine room of ferry ship selat Madura II surabaya, risk management.

ABSTRAK
Risk Management K3 merupakan suatu upaya untuk mengelola risiko Kesehatan dan Keselamatan Kerja (K3) untuk mencegah terjadinya kecelakaan secara sistematis dan terstruktur dengan baik. Tujuan dari penelitian ini adalah melakukan kegiatan risk management pada engine room Kapal Feri Selat Madura II Surabaya. Penelitian ini merupakan penelitian observasional dan merupakan penelitian cross sectional berdasarkan waktu penelitiannya. Objek penelitian ini berfokus pada engine room, dengan populasi seluruh pekerja engine room yang berjumlah 6 orang. Data primer didapatkan melalui hasil observasi dan wawancara yang kemudian dianalisis secara deskriptif.Hasil penelitian menunjukkan bahwa pada engine room terdapat 25 jenis bahaya dengan 5 bahaya termasuk dalam kategori risiko tingkat tinggi atau risiko yang tidak dapat diterima, 20 bahaya merupakan risiko tingkat sedang atau risiko dapat ditolerir, dan 5 bahaya merupakan risiko tingkat rendah atau risiko yang dapat diterima. Upaya pengendalian yang diterapkan adalah pengendalian secara teknik engineering, administratif dan penyediaan Alat Pelingdung Diri (APD). Pengendalian yang paling efektif adalah pengendalian dalam bentuk pemasangan safety device pada mesin, dengan nilai sebesar 90\%. Berdasarkan penilaian risiko sisa, masih terdapat 6 bahaya dengan tingkat risiko sedang.Kesimpulan penelitian ini adalah, dari total 25 macam bahaya pada engine room Kapal Feri Selat Madura II Surabaya , 20\% diantaranya termasuk kedalam bahaya dengan tingkat risiko tinggi atau tidak dapat diterima, namun pengendalian yang diterapkan rata-rata memiliki nilai 90\%, maka dari itu 76\% bahaya dengan kategori risiko tinggi atau tidak dapat diterima dapat diturunkan menjadi kategori dapat diterima.

Kata Kunci: kamar mesin kapal feri selat madura II surabaya, manajemen risiko

\section{PENDAHULUAN}

Mesin merupakan komponen penting dalam terdapat dalam engine room, apabila tidak dirawat, serta berbagai jenis transportasi, tak terkecuali transportasi kapal, bila mengalami kegagalan atau kerusakan berpotensi mulai dari kapal tanker, kapal kargo, kapal perang, kapal menimbulkan kecelakaan kerja.Menurut Peraturan Menteri container, kapal Feri, dan lainnya. Dalam sebuah kapal Tenaga Kerja Nomor: 03/Men/1998 kecelakaan kerja memiliki berbagai macam jenis mesin, serta komponen adalah suatu kejadian yang tidak dikehendaki dan tidak penunjang dimana mesin dan komponen tersebut saling diduga semula yang dapat menimbulkan korban jiwa dan berinteraksiagar kapal dapat beroperasi dengan baik. harta benda. Menurut Baihaqi (2014), sepanjang tahun Berbagai macam mesin tersebut berada dalam satu ruangan 2013, terdapat 129.911 peserta Badan Penyelenggara yang disebut engine room. Menurut Wasimun (2011), Jaminan Sosial (BPJS) Ketenagakerjaan mengalami engine room merupakan suatu ruangan khusus dikapal yang kecelakaan kerja, dimana 33\% diantaranya diakibatkan oleh didalamnya terdapat mesin-mesin, serta muatannya (muat mesin. dan bongkar), termasuk untuk penunjang kehidupan awak kapal dan orang-orang lain diatas kapal.
Pada kapal kecelakaan kerja terutama diakibatkan oleh berbagai macam mesin pada engine room. Menurut 
Raunek (2014), terdapat 10 bahaya ekstrim pada engine room kapal yang mengakibatkan kecelakaan kerja, antara lainledakan engine kapal, gerakan generator yang terlalu cepat, ledakan boiler, ledakan kompresor airline, tekanan tinggi bahan bakar yang menyebabkan ledakan, kebocoran steam, ledakan akibat tekanan tinggi pada hidrolik, ledakan karena turbo charger, masalah kelistrikan, dan kecelakaan akibat tingginya $\mathrm{CO}_{2}$. Berdasarkan hasil penelitian dari Jumali, dkk (2013) menunjukkan hasil dari total 36 engine room kapal sebagai sampel, 64\% diantaranya mempunyai intensitas kebisingan sebesar $>85 \mathrm{~dB}$, selain itu menurut Zaky (2014), pada tahun 2007 sampai tahun 2011, dari total kecelakaan kapal di Indonesia, 48\% disebabkan karena kebakaran atau ledakan. Jumlah kecelakaan kapal di Indonesia menurut hasil keputusan Mahkamah Pelayaran pada tahun 2008 sampai tahun 2012 mencapai 142 kasus kecelakaan, dimana $18 \%$ diantaranya disebabkan oleh kebakaran, serta safety equipment juga menjadi salah satu penyebab dari kecelakaan kapal (Setiono, 2010)

Melihat tingginya angka kecelakaan kerja, serta berbagai macam bahaya pada engine room, maka diperlukan suatu upaya, untuk mencegah terjadinya kecelakaan kerja. Salah satu bentuk upaya dalam mencegah terjadinya kecelakaan kerja adalah dengan melakukan suatu risk management, dengan tujuan untuk mengetahui tingkat risiko suatu pekerjaan, dan efektivitas pengendalian yang telah diterapkan, perusahaan dapat melakukan berbagai upaya untuk mengurangi tingkat risiko, serta mengevaluasi penerapan yang telah dilakukan untuk mengurangi risiko, agar tidak sampai terjadi kecelakaan. Menurut Ramli $\left(2010^{b}\right)$, Risk Management merupakan suatu upaya untuk mengelola risiko $\mathrm{K} 3$ untuk mencegah terjadinya kecelakaan secara sistematis dan terstruktur dengan baik.

Kapal Feri Selat Madura II merupakan perusahaan yang bergerak pada bidang pelayaran dengan jenis kapal penumpang (passenger ship), pada rute penyebrangan Surabaya-Madura. Sama halnya dengan kapal pada umumnya, pada engine room kapal ini, terdapat berbagai macam mesin, yang dapat menimbulkan bahaya dan berisiko terjadinya kecelakaan.

Tujuan dari penelitian ini adalah melakukan kegiatan risk management pada engine room Kapal Feri Selat Madura II Surabaya, mulai dari identifikasi bahaya, melakukan penilaian risiko, penentuan tingkat risiko, melakukan evaluasi risiko, melakukan penilaian pengendalian, serta melakukan perhitungan risiko sisa.

\section{METODE}

Berdasarkan cara pengumpulan datanya, penelitian ini merupakan penelitian obsevasional, karena data diperoleh melalui pengamatan dan wawancara, serta obyek penelitian tidak diberi perlakuan selama penelitian berlangsung. Ditinjau dari sifat masalah dan analisa datanya, maka penelitian ini termasuk penelitian deskriptif, yaitu penelitian dilakukan dengan tujuan untuk membuat gambaran tentang suatu keadaan secara obyektif. Ditinjau dari segi waktu, rancangan penelitian ini termasuk dalam penelitian cross sectional karena wawancara dan pengamatan terhadap variabel dilakukan dilakukan serentak dalam periode waktu tertentu.

Obyek dari penelitian adalah berbagai macam mesin pada engine room Kapal Feri Selat Madura II Surabaya, dengan populasi penelitian seluruh pekerja pada engine room Kapal Feri Selat Madura II Surabaya berjumlah 6 (enam) orang.Lokasi penelitian ini adalah di Kapal Feri Selat Madura II Surabaya, tepatnya pada ruangan kamar mesin atau engine room. Penelitian ini dimulai pada bulan April 2015.

Variabel yang diteliti dalam penelitian ini antara lain adalah bahaya dan risiko yang ditimbulkan dari mesin pada engine room, identifikasi bahaya, penilaian risiko, tingkat risiko, evaluasi risiko, penilaian pengendalian, dan penilaian risiko sisa dari engine room Kapal Feri Selat Madura II Surabaya.

Data yang dikumpulkan dalam penelitian ini adalah data primer dan data sekunder. Data primer didapatkan dengan cara observasi untuk mengetahui bahaya, kondisi mesin, serta kondisi area engine room dan wawancarakepada pekerja, masinis dan Kepala Kamar Mesin (KKM), untuk mengetahui proses yang ada di engine room, potensi bahaya yang mungkin timbul, risiko yang ditimbulkan. Data sekunder yang dikumpulkan adalah mengenai gambaran umum perusahaan, jumlah pekerja, macam mesin dalam engine room, dan petunjuk pengoperasian mesin.

Teknik pengolahan dan analisis data dilakukan berdasarkan dengan tahap risk assessment. Langkah pertama melakukan identifikasi bahaya dengan cara observasi serta wawancara dengan pekerja engine room, setelah itu masing-masing bahaya dicari nilai risiko nya atau Risk Relative melakukan perkalian antara likelihood dan severity, selanjutnya dilakukan penentuan tingkat risiko dengan cara membandingkan nilai Risk Relative dari hasil perkalikan antara likelihood dan severity dengan Risk Assesment Matrix, kemudian hasil dari penentuan tingkat risiko diinterpretasikan. Risk Assesment Matrix terdapat pada Tabel 1.

Tabel 1. Risk Assesment Matrix

\begin{tabular}{cccccc}
\hline \multirow{2}{*}{ Severity } & \multicolumn{5}{c}{ Likelihood } \\
\cline { 2 - 6 } & 1 & 2 & 3 & 4 & 5 \\
\hline 5 & 5 & 10 & 15 & 20 & 25 \\
\hline 4 & 4 & 8 & 12 & 16 & 20 \\
\hline 3 & 3 & 6 & 9 & 12 & 15 \\
\hline 2 & 2 & 4 & 6 & 8 & 10 \\
\hline 1 & 1 & 2 & 3 & 4 & 5 \\
\hline
\end{tabular}

Sumber: Federal Aviation Administration (2010)

Risk Assessment Matrix pada Tabel 1 menunjukkan tiga kategori tingkat risiko. Tingkat risiko dari suatu bahaya. Nilai 1-4 pada warna hijau merupakan tingkat risiko rendah. Nilai 5-14 pada warna kuning merupakan tingkat risiko sedang, dan nilai $15-25$ pada warna merah merupakan tingkat risiko tinggi. Tingkat risiko ini dijadikan 
dasar untuk melakukan evaluasi terhadap risiko, untuk dilihat tingkat penerimaan risiko tersebut.

Tabel 2. Evaluasi Nilai Risiko

\begin{tabular}{|c|c|c|}
\hline $\begin{array}{l}\text { Risiko } \\
\text { Tinggi }\end{array}$ & $\begin{array}{l}\text { Secara umum tidak } \\
\text { dapat diterima }\end{array}$ & $\begin{array}{l}\text { Risiko tidak dapat diterima, kecuali pada kondisi sangat khusus. Kurangi risiko } \\
\text { sampai pada batas dapat diterima. }\end{array}$ \\
\hline $\begin{array}{l}\text { Risiko } \\
\text { Sedang }\end{array}$ & $\begin{array}{l}\text { Basic Safety } \\
\text { Limit }\end{array}$ & $\begin{array}{l}\text { Sisa risiko dapat diterima, hanya jika pengurangan risiko lebih lanjut tidak } \\
\text { memungkinkan }\end{array}$ \\
\hline $\begin{array}{l}\text { Risiko } \\
\text { rendah }\end{array}$ & $\begin{array}{l}\text { Batas aman. } \\
\text { Secara umum } \\
\text { dapat diterima }\end{array}$ & $\begin{array}{l}\text { Pengurangan risiko tidak diperlukan lebih lanjut karena sumber daya yang } \\
\text { dikeluarkan tidak sebanding dengan penurunan risiko }\end{array}$ \\
\hline
\end{tabular}

Sumber: Step Change In Safety, 2007

Tabel 3. Pedoman Penilaian

\begin{tabular}{|c|c|c|}
\hline \multicolumn{2}{|r|}{ Nilai } & Deskripsi \\
\hline $\begin{array}{c}100 \\
\%\end{array}$ & Istimewa & $\begin{array}{l}\text { Persyaratan yang lengkap dari kontrol yang ada dipenuhi dan ditaati dan tidak ada } \\
\text { keraguan bahwa persyaratan tersebut secara penuh diimplementasikan dan berfungsi. }\end{array}$ \\
\hline $90 \%$ & Sangat Baik & Kontrol yang ada diimplementasikan dan berfungsi tetapi masih perlu ditingkatkan. \\
\hline $75 \%$ & $\begin{array}{l}\text { Diimplementasik } \\
\text { an dengan baik }\end{array}$ & $\begin{array}{l}\text { Kontrol yang ada diimplementasikan dan berfungsi. Tetapi, masih ada celah yang } \\
\text { jelas yang harus diperbaiki. }\end{array}$ \\
\hline $65 \%$ & Diimplementasikan & $\begin{array}{l}\text { Persyaratan kontrol yang ada diimplementasikan cukup baik, tetapi masih } \\
\text { memerlukan tindakan spesifik untuk dan terfokus untuk memenuhi persyaratan. }\end{array}$ \\
\hline $50 \%$ & $\begin{array}{l}\text { Diimplementasik } \\
\text { an sebagian }\end{array}$ & $\begin{array}{l}\text { Persyaratan kontrol yang ada telah diimplementasikan sampai taraf tertentu, } \\
\text { memerukan tindakan-tindakan spesifik untuk direncanakan dan diimplementasikan. }\end{array}$ \\
\hline $40 \%$ & $\begin{array}{l}\text { Diimplementasik } \\
\text { an kurang dari } \\
50 \%\end{array}$ & $\begin{array}{l}\text { Walaupun suatu tindakan dilakukan untuk memenuhi suatu item, ada celah-celah } \\
\text { (gaps) yang jelas dan ada kemungkinan kesalah pahaman terhadap beberapa tindakan } \\
\text { spesifik yang masih perlu diambil agar bisa secara semestinya mengimplementasikan } \\
\text { kontrol yang ada. }\end{array}$ \\
\hline $25 \%$ & $\begin{array}{l}\text { Implementasi } \\
\text { lemah }\end{array}$ & $\begin{array}{l}\text { Tidak ada tindakan riil yang telah diambil untuk mengimplementasikan persyaratan. } \\
\text { Jelas bahwa hal-hal tertentu dari persyaratan tidak dipahami. Intervensi spesifik harus } \\
\text { diambil untuk memastikan bahwa kemajuan dibuat untuk mengimplementasikan } \\
\text { persyaratan. }\end{array}$ \\
\hline $15 \%$ & Ada pengertian & $\begin{array}{l}\text { Ada pengertian bahwa tindakan harus diambil tetapi hingga tanggal ini tidak ada } \\
\text { sesuatu yang telah dilakukan untuk mengimplemntasikan persyaratan kontrol yang } \\
\text { ada. }\end{array}$ \\
\hline $0 \%$ & $\begin{array}{l}\text { Tidak } \\
\text { diimplementasikan }\end{array}$ & $\begin{array}{l}\text { Tidak ada yang dilakukan sampai tanggal ini untuk diimplementasikan persyaratan } \\
\text { kontrol yang ada. Tidak ada pertimbangan implementasi dalam waktu dekat. } \\
\text { Pengertian tentang persyaratan mungkin ada, tetapi tidak ada tindakan spesifik untuk } \\
\text { memenuhinya. }\end{array}$ \\
\hline
\end{tabular}

Sumber: HSE PT.Freeport Indonesia (2008)

Langkah selanjutnya setelah mengetahui tingkat dapat diterima. Risiko yang termasuk dalam kategori secara risiko, adalah melakukan evaluasi risiko. Tahap evaluasi umum dapat diterima merupakan risiko dengan kategori risiko bertujuan untuk melakukan evaluasi terhadap suatu tingkat risiko rendah. Risiko dapat diterima ini merupakan risiko, apakah risiko tersebut dapat diterima atau tidak. batas aman, artinya pekerja dapat bekerja secara aman Oleh karena itu, sebagai tindak lanjut harus ditentukan apabila bahaya pada lingkungan kerjanya termasuk prioritas risiko atau peringkat risikonya (Ramli, 2010). kedalam tingkat risiko rendah, sehingga tidak diperlukan Pendekatan yang digunakan dalam melakukan evaluasi suatu upaya pengurangan risiko lebih lanjut, karena jumlah risiko adalah dengan menggunakan konsep As Low As sumber daya yang tidak memungkinkan. Kategori Reasonably Practicable (ALARP). Dalam konsep ALARP selanjutnya adalah kategori risiko dapat ditolerir. Dapat menekankan pengertian tentang "practicable" atau praktis ditolerir artinya risiko dapat diterima, hanya apabila untuk dilaksanakan yang artinya pengendalian risiko pengurangan risiko namun pada kenyataannya perlu tersebut dapat dikerjakan atau dilaksanakan dalam konsep dilakukan berbagai macam upaya sebisa mungkin agar biaya, manfaat, interaksi, dan operasionalnya. Konsep risiko tersebut menjadi dapat diterima. Risiko yang ALARP atau pedoman evaluasi nilai risiko dapat dilihat termasuk kedalam kategori dapat ditolerir merupakan risiko pada Tabel $2 . \quad$ dengan kategori tingkat risiko sedang. Kategori selanjutnya

Tabel 2 menunjukkan terdapat tiga kategori dalam adalah kategori tidak dapat diterima. Risiko yang termasuk evaluasi risiko. Kategori pertama adalah risiko rendah atau kedalam kategori tidak dapat diterima merupakan risiko 
dengan kategori tingkat risiko tinggi. Kategori risiko tidak terakhir adalah penghitungan nilai risiko sisa (residual dapat diterima harus dilakukan upaya pengendalian karena risk). Nilai risiko sisa dihitung dengan menggunakan dapat membahayakan pekerja apabila tidak dilakukan rumus sebagai berikut: tindak lanjut.

Langkah selanjutnya dalam analisis risiko adalah melakukan penilaian terhadap pengendalian risiko yang ada. Dalam melakukan penilaian, digunakan pedoman dari PT.Freeport Indonesia (2008), dalam Tualeka (2013). Pedoman penilaian dapat dilihat pada Tabel 3. Langkah HASIL

\section{Identifikasi Bahaya}

Identifikasi bahaya dilakukan agar dapat mengetahui bahaya yang ditimbulkan dari berbagai macam komponen dalam engine room yang berpotensi mengakibatkan kecelakaan kerja. Teknik identifikasi yang digunakan dalam penelitian di engine room Kapal Feri Selat Madura II adalah Failure Mode and Effect Analysis, dimana teknik tersebut digunakan pada kondisi dimana bahaya bersumber dari mesin mekanik, serta dapat menganalisi potensi kegagalan apa yang dapat terjadi pada mesin tersebut.

Dari berbagai macam komponen yang menimbulkan bahaya diperoleh dari hasil wawancara dengan Kepala Kamar Mesin (KKM) dan observasi. Dari 10 macam komponen mesin yang ada di engine room, ada 7 komponen yang menimbulkan bahaya. Komponen tersebut yaitu mesin induk, mesin bantu/kelistrikan, pompa pendingin, pompa oil water separator (OWS), tangki, blower dan panel listrik.

$$
\frac{(100 \%-\% \text { nilai kontrol }) \times \text { risiko }}{100 \%}
$$

yang terlalu tinggi, pipa bahan bakar pecah, manifold overheat, serta bahaya dari perputaran flywheel, dan rotor.

Mesin bantu/kelistrikan berpotensi mengalami kegagalan atau menimbulkan bahaya pendingin mesin yang tidak stabil, kebocoran bahan bakar, kebocoran oli, tekanan oli terlalu tinggi, pipa bahan bakar pecah, manifold overheat, uap panas muncul dari filter udara, kabel dinamo tidak tertata rapi, dan isolasi kabel terlepas

Potensi kegagalan dan bahaya yang dapat terjadi pada pompa pendingin adalah kebocoran air dan tekanan air kurang. Pada pompa Oil Water Separator (OWS) potensi kegagalan dan bahaya yang dapat terjadi adalah kabel yang tidak tertata dengan semestinya dan kebocoran oli.

Tangki dalam engine room atau biasa disebut tangki harian, berfungsi sebagai penyimpanan bahan bakar kapal.Potensi kegagalan yang dapat terjadi pada tangki adalah terjadinya kebocoran bahan bakar. Blower berfungsi sebagai sirkulasi udara engine room, terutama pada control room, serta untuk mendinginkan mesin. Letak jalur blower yang pada engine room tidak terlalu tinggi, sehingga

Mesin induk berpotensi mengalami kegagalan atau pekerja dapat terbentur jalur blower tersebut. Potensi menimbulkan bahaya berupa pendingin mesin yang tidak kegagalan dan bahaya yang terjadi pada panel listrik adalah stabil, kebocoran bahan bakar, kebocoran oli, tekanan oli sambungan antar kabel atau komponen yang kendor, dan pengamanan panel terlepas.

\section{Penilaian Risiko}

selanjutnya dicatat dalam Risk assessment Table. Risk

Proses penilaian risiko dilakukan dengan cara Relative ini berfungsi untuk mengetahui tingkat dari risiko mencari nilai Risk Relative. Risk Relative merupakan hasil masing-masing bahaya. Berdasarkan hasil penilaian risiko, dari perkalian antara nilai tingkat keseringan (likelihood) terdapat $20 \%$ mempunyai nilai Risk Relative tinggi, $60 \%$ dengan nilai tingkat keparahan (severity), dari masing-mempunyai nilai Risk Relative sedang, dan 20\% masing bahaya. Setelah nilai Risk Relative didapat, mempunyai nilai Risk Relative rendah.

\section{Tingkat Risiko}

Tingkat risiko dari suatu bahaya dapat dilihat dari nilai Risk Relative, dimana untuk nilai Risk Relative dibandingkan dengan Risk assessment Matrix. Nilai Risk Relative 1-4 maka termasuk kategori rendah, 5-14 termasuk kategori sedang, dan 15-25 termasuk dalam kategori tinggi. Berdasarkan hasil, dari total 25 risiko yang diakibatkan oleh 25 bahaya, sebanyak 20\% risiko termasuk kategori tinggi, $60 \%$ termasuk dalam kategori sedang, dan $20 \%$ risiko termasuk dalam kategori rendah.

Risiko yang termasuk kedalam tingkat risiko tinggi adalah risiko terpapar panas oleh manifold mesin induk, risiko tergilas oleh perputaran flywheel pada mesin induk, risiko tergilas oleh perpuataran rotor mesin induk, risiko kebakaran karena kebocoran oli mesin bantu, dan risiko terpapar panas oleh manifold mesin bantu.
Risiko yang termasuk kedalam kategori tingkat risiko sedang adalah, risiko ledakan akibat ketidakstabilan

pendingin mesin induk, risiko kebakaran akibat kebocoran bahan bakar mesin induk, risiko kebakaran akibat kebocoran oli mesin induk, risiko ledakan akibat tekanan oli mesin induk terlalu tinggi, risiko kebakaran akibat pipa bahan bakar mesin induk pecah, risiko ledakan akibat ketidakstabilan pendingin mesin bantu, risiko kebakaran akibat kebocoran bahan bakar mesin bantu, risiko ledakan akibat tekanan oli mesin bantu terlalu tinggi, risiko kebakaran akibat pipa bahan bakar mesin bantu pecah, dan sebagainya

Risiko yang termasuk kedalam kategori tingkat risiko rendah adalah risiko terpapar uap panas filter udara, risiko tersandung kabel dinamo mesin bantu, risiko tersandung kabel pompa Oil Water Separator (OWS), risiko terpeleset akibat oli berceceran pada pompa Oil 
Water Separator (OWS), dan risiko tersetrum pada panel tabel 3.

listrik. Selengkapnya penilaian tingkat risiko disajikan pada

Tabel 3. Tingkat Risiko Pada Engine Room Kapal Feri Selat Madura II Surabaya

\begin{tabular}{|c|c|c|c|c|c|}
\hline \multirow[b]{2}{*}{ KOMPONEN } & \multirow[b]{2}{*}{$\begin{array}{l}\text { FAILURE MODE } \\
\text { ATAU BAHAYA }\end{array}$} & \multirow[b]{2}{*}{ RISIKO } & \multicolumn{2}{|c|}{ RISK MATRIX } & \multirow[b]{2}{*}{$\begin{array}{l}\text { TINGKAT } \\
\text { RISIKO }\end{array}$} \\
\hline & & & $\begin{array}{c}\text { LIKE- } \\
L I H O O D\end{array}$ & SEVERITY & \\
\hline \multirow{8}{*}{ Mesin Induk } & Ketidakstabilan pendingin & Ledakan & 1 & 5 & Sedang \\
\hline & Kebocoran bahan bakar & Kebakaran & 1 & 5 & Sedang \\
\hline & Kebocoran Oli & Kebakaran & 1 & 5 & Sedang \\
\hline & Tekanan Oli terlalu tinggi & Ledakan & 1 & 5 & Sedang \\
\hline & Manifold overheat & Terpapar panas & 5 & 3 & Tinggi \\
\hline & Pipa Bahan Bakar pecah & Kebakaran & 1 & 5 & Sedang \\
\hline & Perputaran flywheel & Tergilas & 5 & 5 & Tinggi \\
\hline & Perputaran Rotor & Tergilas & 5 & 5 & Tinggi \\
\hline \multirow{9}{*}{$\begin{array}{l}\text { esin Bantu/Mesin } \\
\text { Kelistrikan }\end{array}$} & Ketidakstabilan pendingin & Ledakan & 1 & 5 & Sedang \\
\hline & Kebocoran bahan bakar & Kebakaran & 1 & 5 & Sedang \\
\hline & Kebocoran oli & Kebakaran & 4 & 5 & Tinggi \\
\hline & Tekanan Oli terlalu tinggi & Ledakan & 1 & 5 & Sedang \\
\hline & Pipa Bahan Bakar pecah & Kebakaran & 1 & 5 & Sedang \\
\hline & Manifold overheat & Terpapar panas & 5 & 3 & Tinggi \\
\hline & Uap panas dari filter udara & Terpapar Uap panas & 1 & 3 & Rendah \\
\hline & $\begin{array}{l}\text { Kabel Dinamo Tidak } \\
\text { tertata rapi }\end{array}$ & Tersandung & 1 & 1 & Rendah \\
\hline & Isolasi kabel terkelupas & Tersetrum & 1 & 5 & Sedang \\
\hline \multirow{2}{*}{$\begin{array}{l}\text { Pompa Pendingin } \\
\text { air laut \& tawar }\end{array}$} & Kebocoran air & Terpeleset & 5 & 1 & Sedang \\
\hline & Komponen pompa kotor & Ledakan & 1 & 5 & Sedang \\
\hline \multirow{2}{*}{$\begin{array}{c}\text { Pompa Oil } \\
\text { Water } \\
\text { Separator }\end{array}$} & Kabel berserakan & Tersandung & 1 & 1 & Rendah \\
\hline & Oli berceceran & Terpeleset & 4 & 1 & Rendah \\
\hline Tanki & Kebocoran bahan bakar & Kebakaran & 1 & 5 & Sedang \\
\hline Blower & Letak saluran blower pendek & Terbentur & 5 & 2 & Sedang \\
\hline \multirow[t]{2}{*}{ Panel Listrik } & $\begin{array}{l}\text { Sambungan antar kabel } \\
\text { kendor }\end{array}$ & Kebakaran & 1 & 5 & Sedang \\
\hline & Pengamanan terlepas & Tersetrum & 1 & 4 & Rendah \\
\hline
\end{tabular}

\section{Evaluasi Risiko}

Evaluasi risiko dilakukan untuk menilai apakah dengan tingkat risiko rendah.

risiko tersebut dapat diterima atau tidak yang dikategorikan kedalam 3 kategori yaitu risiko dapat diterima (generally acceptable), risiko dapat ditolerir (tolerable), dan risiko tidak dapat diterima (generally unacceptable), atau dikenal dengan sebutan ALARP (As Low As Reasonably Practicable). Risiko yang dapat diterima merupakan risiko tingkat rendah, sedangkan risiko yang dapat ditolerir merupakan risiko tingkat sedang, dan risiko yang tidak dapat diterima merupakan risiko tingkat tinggi. Hasil evaluasi risiko menunjukkan bahwa dari total 25 risiko yang telah dikategorikan, terdapat $20 \%$ risiko yang tidak dapat diterima, $60 \%$ risiko dapat ditolerir dan $20 \%$ risiko yang dapat diterima.Risiko yang termasuk kedalam kategori tidak dapat diterima merupakan risiko dengan tingkat risiko tinggi. Risiko yang termasuk kedalam kategori dapat ditolerir merupakan risiko dengan tingkat risiko sedang, dan risiko yang

\section{Pengendalian Risiko}

Upaya pengendalian risiko yang telah diterapkan pada engine room Kapal Feri Selat Madura II Surabaya adalah pengendalian secara teknik engineering, pengendalian administratif dan penyediaan Alat Pelingdung Diri (APD) bagi pekerja. Pengendalian secara teknik engineering adalah pemasangan safety device pada beberapa mesin. Pengendalian secara administratif adalah dengan melakukan pergantian berjaga pada control room engine room, serta pengaturan jam kerja. Pengendalian terakhir berupa Alat Pelindung Diri (APD) bagi pekerja, disediakan coverall, safety gloves, safety shoes, safety helmet, dan lainnya.

\section{Risiko Sisa}


Berdasarkan hasil penilaian risiko sisa, setelahterutama pada pipa sambungan dari mesin ke tangki. diterapkan pengendalian risiko masih ada $24 \%$ risiko yangelain kebocoran bahan bakar, kebakaran juga diakibatkan termasuk dalam kategori sedang atau dapat ditoleriroleh kebocoran oli pada mesin induk dan bantu. Karena oli sedangkan 76\% sisanya, risiko sudah dapat diterima atamerupakan pelumas dari mesin, maka dari itu sangat masuk kategori tingkat risiko rendah

\section{PEMBAHASAN}

\section{Identifikasi Bahaya}

Langkah pertama dalam melakukan risk assessment adalah melakukan identifikasi bahaya. Menurut OHSAS 18001 dalam Ramli $\left(2010^{\mathrm{a}}\right)$, identifikasi bahaya merupakan proses untuk mengetahui suatu bahaya dan karakteristiknya. Terdapat berbagai macam metode dalam melakukan identifikasi bahaya. Pada engine room Kapal Feri Selat Madura II Surabaya dilakukan identifikasi bahaya dengan metode Failure Mode And Effect Analisis (FMEA). FMEA merupakan suatu metode yang digunakan untuk menganalisis sistem yang berhubungan dengan engine yang mungkin mengalami kegagalan dan efek yang ditimbulkan dari kegagalan (Tualeka, 2013).

Proses identifikasi bahaya pada engine room Kapal Feri Selat Madura II Surabaya dilakukan dengan cara observasi dan wawancara dengan pekerja engine room yang berjumlah 6 orang, lalu hasil observasi dan wawancara tersebut dicatat pada Risk Assessment Table. Berdasarkan identifikasi bahaya yang telah dilakukan, pada engine room Kapal Feri Selat Madura II Surabaya, didominasi oleh bahaya yang menyebabkan risiko terjadinya ledakan dan kebakaran. Bahaya yang mengakibatkan ledakan bersumber pada mesin bantu, mesin induk, dan pompa pendingin air laut dan tawar, sedangkan bahaya yang menyebabkan kebakaran bersumber pada mesin induk, mesin bantu, tangki, dan panel listrik

Bahaya ketidakstabilan pendingin ada mesin induk dan mesin bantu dapat menyebabkan ledakan. Sama halnya dengan mesin pada umumnya, mesin induk dan mesin bantu membutuhkan air untuk menjaga suhu pada ambang batas normal, yaitu $70^{\circ} \mathrm{C}$. Apabila suhu mesin telah melebihi $70^{\circ} \mathrm{C}$ akan mengakibatkan overheat. Jika overheat terus berlangsung maka mesin dapat meledak. Selain itu tekanan oli pada mesin induk dan mesin bantuyang terlalu tinggi dapat mengakibatkan overheat. Dan apabila overheat tersebut terus berlangsung dapat mengakibatkan ledakan pada mesin induk. Pada pompa pendingin air laut dan tawar, apabila komponen didalamnya kotor dapat mengakibatkan pompa tidak bekerja secara maksimal, dimana tekanan air menjadi tinggi. Tekanan air yang tinggi, apabila dibiarkan dapat mengakibatkan ledakan pada pompa pendingin air laut dan tawar.

Kebocoran bahan bakar merupakan penyebab salah satu terjadinya kebakaran pada kapal. Kebocoran ini dapat terjadi pada mesin induk, mesin bantu dan juga tangki. Mesin induk dan mesin bantu membutuhkan bahan bakar agar dapat beroperasi, maka dari itu potensi kegagalan kebocoran dapat terjadi pada kedua mesin tersebut mungkin terjadi kebocoran oli pada mesin induk dan bantu.

Selain karena kebocoran, kebakaran dapat disebabkan pecahnya pipa bahan bakar mesin induk dan mesin bantu. Dari tangki bahan bakar disuplai ke mesin dengan bantuan pipa. Karena letaknya berdekatan dengan manifold, dan sifat dari manifold adalah panas, maka lama-kelamaan pipa bahan bakar dapat pecah. Apabila pipa bahan bakar pecah maka dapat terjadi kebakaran.

Pada panel listrik, di dalamnya terdapat berbagai macam kabel yang jumlahnya banyak.Berbagai macam kabel tersebut saling menyambung dengan panel agar bisa beroperasi. Jika sambungan tidak erat, baik antara kabel dengan panel maupun antar kabel satu demgam yang lain, maka dapat mengakibatkan aliran listrik terbuka dan dapat mengakibatkan kebakaran.

\section{Penilaian Risiko}

Langkah selanjutnya dalam analisis risiko setelah melakukan proses identifikasi bahaya, adalah melakukan penilaian risiko. Penilaian risiko merupakan suatu proses dalam menentukan prioritas pengendalian terhadap tingkat risiko kecelakaan kerja atau penyakit akibat kerja (Permenkes 05/Men/1996). Proses penilaian risiko pada engine room kapal Feri dilakukan dengan cara wawancara kepada pekerja engine room. Pada proses wawancara pekerja diberikan tabel berisi skala likelihood dan severity, sehingga pekerja dapat mengetahui tingkat kategori dari likelihood dan severity. Setelah nilai likelihood dan severity didapat, lalu dicatat pada Risk Assessment Table. Hasil penilaian risiko menunjukkan bahwa, terdapat $20 \%$ risiko memiliki nilai $20 \%$ mempunyai nilai Risk Relative tinggi.

Risiko pertama yang mempunyai nilai Risk Relative tinggi adalah risiko tergilas flywheel mesin induk. Nilai likelihood dari bahaya yang timbul dari roda gila (flywheel) pada mesin induk adalah 5, hal ini dikarenakan flywheel selalu berputar setiap hari. Tergilas merupakan dampak yang fatal akibat dari perputaran flywheel, maka dari itu nilai severity nya 5, dengan kategori catastrophic. Nilai Risk Relative dari bahaya ini adalah 25 .

Risiko kedua yang mempunyai nilai Risk Relative tinggi adalah risiko tergilas oleh perpuataran rotor mesin induk. Rotor pada mesin induk juga berputar setiap hari, yang berdampak jari pekerja terpotong/tergilas, maka dari itu nilai likelihood dari bahaya akibat putaran rotor adalah 5, dan nilai severitynya 5, dengan kategori keparahan catastrophic. Hasil dari perkalian antara nilai likelihood 5 dengan nilai severity 5 , menghasilkan nilai Risk Relative 25.

Risiko ketiga yang mempunyai nilai Risk Relative tinggi adalah risiko kebakaran karena kebocoran oli mesin bantu. Berdasarkan wawancara, kebocoran oli pada mesin bantu pernah terjadi lebih dari seminggu sekali atau kemungkinan terjadi bahaya pada suatu keadaan tertentu. nilai likelihood untuk peluang seperti ini adalah 4. Apabila oli 
bocor, dapat memicu terjadinya kebakaran, dan apabilalalam Tualeka (2013) nilai Risk Relative 25 termasuk kebakaran tersebut terjadi maka dampaknya fatal, dan luaslalam kategori risiko tinggi.

maka dari itu nilai severity nya 5. Nilai Risk Relative dari Risiko ketiga yang termasuk dalam tingkat risiko perkalian likelihood dan severity bahaya kebocoran olitinggi adalah risiko tergilas oleh perpuataran rotor mesin sebesar 20.

induk. Hasil perhitungan Risk Relative untuk risiko tergilas

Risiko keempat yang mempunyai nilai Risk pitaran rotor sebesar 25. Apabila dibandingkan dengan Relative tinggi adalah adalah risiko terpapar panas oleh kategori risiko menurut Federal Aviation Administration manifold mesin induk. Letak manifold tiap harinya tidak (2010), dalam Tualeka (2013), maka termasuk dalam kategori berpindah, hanya pada area tertentu saja, maka dari itu risiko tinggi.

peluang terjadinya bahaya adalah tiap hari, berarti nilai likelihood dari bahaya ini adalah 5.Apabila pekerja terpapar panas dari suhu manifold dapat mengakibatkan cedera yang membutuhkan penanganan medis. Maka bahaya ini termasuk dalam kategori keparahan moderate, dengan nilai severity 3. Hasil perkalian dari likelihood dan severity bahaya ini, menghasilkan nilai Risk Relative 15 .

Risiko kelima yang mempunyai nilai Risk Relative tinggi adalah risiko terpapar panas oleh manifold mesin bantu. Letak manifold pada mesin bantu tiap harinya tidak berpindah, hanya pada area tertentu saja, maka dari itu peluang terjadinya bahaya adalah tiap hari, berarti nilai likelihood dari bahaya ini adalah 5. Seorang pekerja bila terpapar panas dari suhu manifold dapat mengakibatkan cedera yang membutuhkan penanganan medis, maka dari itu bahaya ini termasuk dalam kategori keparahan moderate, dengan nilai severity 3 . Hasil perkalian dari likelihood dan severity bahaya ini, menghasilkan nilai Risk Relative 15.

\section{Tingkat Risiko}

Langkah selanjutnya setelah mengetahui nilai Risk Relative adalah menentukan tingkat risiko. Menurut Federal Aviation Administration (2010) dalam Tualeka (2013), risiko yang termasuk kedalam kategori tingkat risiko rendah merupakan risiko dengan nilai Risk Relative 1-4, sedangkan risiko yang termasuk kedalam kategori tingkat risiko sedang merupakan risiko dengan nilai Risk Relative 5-14, dan risiko yang termasuk dalam kategori tingkat risiko tinggi merupakan risiko dengan nilai Risk Relative 15-25.

Hasil penentuan tingkat risiko pada engine room Kapal Feri Selat Madura II Surabaya, dari total 25 risiko kecelakaan yang diakibatkan 25 bahaya, terdapat $20 \%$ bahaya yang termasuk dalam kategori tingkat risiko tinggi.

Risiko pertama yang termasuk dalam tingkat risiko tinggi adalah risiko terpapar panas oleh manifold mesin induk. Nilai Risk Relative dari risiko terpapar panas oleh manifold mesin induk yaitu 15. Menurut Federal Aviation Administration (2010), dalam Tualeka (2013) nilai Risk Relative 15 termasuk dalam kategori risiko tinggi, karena kategori risiko tinggi merupakan risiko dengan nilai Risk Relative antara 15-25.

Risiko kedua yang termasuk dalam tingkat risiko tinggi adalah risiko tergilas oleh perputaran flywheel pada mesin induk.Berdasarkan hasil penilaian risiko nilai Risk Relative dari risiko tergilas oleh putara flywheel sebesar 25. Menurut Federal Aviation Administration (2010),

Risiko keempat yang termasuk dalam tingkat risiko tinggi adalah risiko kebakaran karena kebocoran oli pada mesin bantu. Hasil perhitungan nilai Risk Relative untuk risiko kebakaran karena kebocoran oli pada mesin bantu adalah 20. Nilai 20 apabila dimasukkan kedalam kategori tingkat risiko termasuk kedalam kategori risiko tinggi.

Risiko kelima yang termasuk dalam tingkat risiko tinggi adalah risiko terpapar panas oleh manifold mesin bantu. Risiko terpapar panas oleh manifold termsuk kedalam kategori risiko tinggi, karena hasil perhitungan Risk Relative adalah 15 , dimana 15 nerada di antara range kategori risiko tinggi yaitu 15-25.

\section{Evaluasi Risiko}

Berdasarkan hasil evaluasi risiko pada engine room Kapal Feri Selat Madura II Surabaya, terdapat 20\% risiko termasuk risiko yang tidak dapat diterima. Risiko pertama yang termasuk dalam kategori risiko tidak dapat diterima adalah risiko terpapar panas oleh manifold mesin induk. Berdasarkan penilaian tingkat risiko, risiko ini termasuk kedalam tingkat risiko tinggi.Berdasarkan konsep ALARP tingkat risiko tinggi bila dievaluasi termasuk dalam kategori risiko tidak dapat diterima, maka dari itu pihak kapal wajib mengurangi risiko sampai pada batas dapat diterima.

Risiko kedua yang termasuk dalam kategori risiko tidak dapat diterima adalah risiko tergilas oleh perputaran flywheel pada mesin induk.Berdasarkan penilaian tingkat risiko, risiko ini termasuk kedalam tingkat risiko tinggi. Berdasarkan konsep ALARP tingkat risiko tinggi bila dievaluasi termasuk dalam kategori risiko tidak dapat diterima, maka dari itu pihak kapal wajib mengurangi risiko sampai pada batas dapat diterima.

Risiko ketiga yang termasuk dalam kategori risiko tidak dapat diterima adalahrisiko tergilas oleh perpuataran rotor mesin induk. Berdasarkan penilaian tingkat risiko, risiko ini termasuk kedalam tingkat risiko tinggi. Berdasarkan konsep ALARP tingkat risiko tinggi bila dievaluasi termasuk dalam kategori risiko tidak dapat diterima, maka dari itu pihak kapal wajib mengurangi risiko sampai pada batas dapat diterima.

Risiko keempat yang termasuk dalam kategori risiko tidak dapat diterima adalahrisiko kebakaran karena kebocoran oli pada mesin bantu. Berdasarkan penilaian tingkat risiko, risiko ini termasuk kedalam tingkat risiko tinggi. Berdasarkan konsep ALARP tingkat risiko tinggi bila dievaluasi termasuk dalam kategori risiko tidak dapat diterima, maka dari itu pihak kapal wajib mengurangi risiko sampai pada batas dapat diterima. 
Risiko kelima yang termasuk dalam kategori risikøerpapar panas oleh manifold adalah menyediakan APD tidak dapat diterima adalahrisiko terpapar panas olelberupa safety gloves kepada pekerja, agar jika pekerja manifold mesin bantu. Berdasarkan penilaian tingkat risikotidak sengaja memegang manifold, dampaknya tidak risiko ini termasuk kedalam tingkat risiko tinggi.Berdasarkanterlalu parah, namun pemakaian safety gloves pada pekerja konsep ALARP tingkat risiko tinggi bila dievaluasi termasulbelum sempurna. Berdasarkan wawancara nilai efektivitas dalam kategori risiko tidak dapat diterima, maka dari itpengendalian ini sebesar 50\%, yang berarti perlu tindakan pihak kapal wajib mengurangi risiko sampai pada batas dapatanjut baik untuk membuat pekerja lebih disiplin memakai diterima.

safety gloves atau mencari pengendalian lain.

\section{Penilaian Pengendalian}

Wawancara dengan Kepala Kamar Mesin dilakukan untuk mencari upaya pengendalian pada engine room Kapal Feri Selat Madura II Surabaya, begitu juga untuk menilai efektivitas pengendalian tersebut juga dilakukan wawancara dengan Kepala Kamar Mesin. Pengendalian risiko dan penilaiannya merupakan tahap penting dari Risk Management. Menurut OHSAS 18001 dalam Ramli $\left(2010^{\mathrm{a}}\right)$, macam pengendalian bahaya K3 antara lain pengendalian secara eliminasi, subtitusi, teknik engineering, administratif dan penyediaan Alat Pelindung Diri (APD). Pengendalian secara eliminasi pada engine room Kapal Feri Selat Madura II Surabaya tidak mungkin dilakukan, karena tidak dapat menghilangkan komponen yang menjadi sumber yang menimbulkan bahaya. Begitu juga subtitusi, mengganti berbagai komponen serta mesin dengan jenis yang baru juga tidak mungkin, karena butuh pertimbangan dari berbagai pihak mulai dari biaya dan lain sebagainya.

Mesin induk mempunyai 3 risiko yang tidak dapat diterima. Risiko yang tidak dapat diterima dari bahaya yang bersumber pada mesin induk adalah risiko terpapar panas manifold overheat, risiko tergilas putaran flywheel dan risiko tergilas putaran rotor. Bentuk pengendalian untuk mengurangi risiko terpapar panas manifold overheat, adalah menggunakan safety gloves bagi pekerja, namun belum sepenuhnya diterapkan, perlu tindakan lebih lanjut. Berdasarkan Tabel 3 pedoman pengendalian yang baru diimplementasikan sebagian, dan perlu tindakan lanjut, memiliki nilai efektivitas sebesar $50 \%$.

Bentuk pengendalian untuk risiko tergilas putaran flywheel adalah safety gloves, dan seharusnya memberi safety sign. Namun implementasi pengendalian tersebut masih lemah. Untuk pengendalian dalam rangka mengurangi risiko tergilas putaran rotor, adalah pemasangan barrier untuk melingdungi penutup rotor agar tidak terkena pekerja. Pengendalian ini telah diimplementasikan dengan sangat baik, maka dari itu memiliki nilai efektivitas sebesar $90 \%$.

Mesin bantu mempunyai 2 risiko yang tidak dapat diterima. Risiko yang tidak dapat diterima akibat bahaya dari mesin bantu adalah risiko ledakan akibat kebocoran oli, dan risiko terpapar panas oleh manifold. Pengendalian untuk mengurangi risiko ledakan akibat kebocoran oli mesin bantu adalah memberi tempat sekitar pipa sambungan untuk menampung kebocoran, dan menerapkan tanggap darurat kebakaran. Implementasi dair pengendalian ini sudah baik, maka dari itu nilai pengendalian nya sebesar $75 \%$. Upaya pengendalian risiko

\section{Risiko Sisa}

Hasil penilaian risiko sisa menunjukkan, dari 25 risiko yang telah dilakukan upaya pengendalian, masih terdapat $24 \%$ risiko yang termasuk dalam kategori sedang, atau termasuk dalam kategori risiko yang dapat ditolerir, sedangkan sisanya termasuk dalam kategori risiko rendah, atau risiko yang dapat diterima.

Menurut Siswanto (2009) dalam Tualeka (2013) risiko sisa adalah risiko yang masih ada setelah pengendalian. Pengendalian risiko yang baik dan dianggap dapat diterima, apabila nilai risiko sisa dari pengendalian tersebut lebih rendah ataui sama dengan peringkat tingkat risiko murni (Ramli, 2010 ${ }^{\mathrm{b}}$.

Risiko pertama yang termasuk kategori risiko dapat ditolerir yaitu risiko terpapar panas oleh manifold mesin induk. Risiko terpapar panas oleh manifold mesin induk, memiliki nilai Risk Relative sebesar 15. Nilai upaya pengendalian berupa pengadaan safety gloves sebesar $50 \%$. Jika dihitung memakai rumus, didapat hasil 8. Nilai risiko sisa 8 termasuk dalam kategori risiko sedang atau risiko dapat ditolerir.

Risiko kedua yang termasuk dalam kategori risiko dapat ditolerir adalah risiko tergilas oleh perputaran flywheel pada mesin induk.Hasil penilaian evaluasi risiko menunjukan bahwa risiko tergilas oleh perputaran flywheel pada mesin induk, merupakan kategori risiko yang tidak dapat diterima. Nilai Risk Relative dari risiko Tergilas oleh perputaran flywheel pada mesin induk sebesar 25, sedangkan nilai pengendalian berupa pemasangan safety sign dan penyediaan APD safety gloves sebesar 50\%. Apabila dihitung menggunakan rumus sesuai Siswanto (2009) dalam Tualeka (2013), maka hasilnya 13.Nilai 13 termasuk dalam tingkat kategori sedang dan merupakan risiko dapat ditolerir.

Risiko ketiga yang termasuk dalam kategori risiko dapat ditolerir adalah risiko kebakaran akibat kebocoran oli mesin bantu. Nilai pengendalian untuk mengurangi risiko terpeleset akibat kebocoran oli mesin bantu sebesar 40\%, sedangkan nilai Risk Relativenya sebesar 8. Jika dihitung menggunakan rumus maka hasil penilaian risiko sisa pada risiko terpeleset akibat kebocoran oli mesin bantu adalah 5, termasuk kedalam tingkat risiko sedang atau dapat diterima.

Risiko keempat yang termasuk dalam kategori risiko dapat ditolerir yaitu risiko terpapar panas oleh manifold mesin bantu. Risiko terpapar panas oleh manifold mesin bantu, mempunyai nilai Risk Relative sebesar 15. Nilai upaya pengendalian berupa pengadaan safety gloves sebesar $50 \%$. Apabila dihitung dengan menggunakan rumus, maka hasil nya didapat adalah 8 .Nilai risiko sisa 8 termasuk dalam kategori risiko sedang, atau risiko dapat ditolerir. 
Risiko kelima yang termasuk dalam kategori risiko dapat ditolerir adalah risiko terpeleset kebocoran air pompa pendingin air laut dan tawar. Nilai dari Risk Relative risiko terpeleset akibat kebocoran air pompa pendingin air laut dan tawar adalah 5, sedangkan nilai pengendalian risiko $10 \%$. Bila dihitung memakai rumus penilaian risiko sisa, hasil penilaian risiko sisa adalah 5.Nilai 5 tersebut termasuk kedalam kategori risiko sedang atau risiko dapat ditolerir.

Risiko keenam yang termasuk dalam kategori risiko dapat ditolerir adalah risiko terbentur oleh saluran blower yang memiliki nilai Risk Relative sebesar 8 dan nilai pengendaliannya sebesar $0 \%$. Karena tidak ada pengendalian berupa safety sign atau yang lain, maka hasil penilaian risiko sisa adalah 8 , dan termasuk dalam tingkat risiko sedang atau risiko dapat diterima.

\section{KESIMPULAN DAN SARAN}

Hasil identifikasi bahaya yang telah dilakukan menunjukkan, dari 10 macam mesin yang ada pada engine room Kapal Feri Selat Madura II Surabaya, terdapat 7 macam mesin yang menimbulkan bahaya. Berdasarkan penilaian risiko, sebagian besar bahaya memiliki nilai Risk Relative tinggi. Tingkat risiko pada engine room Kapal Feri Selat Madura II Surabaya didominasi oleh kategori tingkat risiko sedang. Setelah dilakukan eveluasi risiko, sebagian besar risiko termasuk kedalam kategori risiko yang dapat ditolerir. Pengendalian yang telah diterapkan pada engine room Kapal Feri Selat Madura II Surabaya adalah pengendalian secara teknik engineering berupa pemasangan safety device yang berfungsi sebagai alarm jika mesin mengalami overheat, pengendalian administratif berupa pengaturan waktu pekerja berada di control room dan penyediaan APD berupa safety gloves, dan ear plug. Hasil perhitungan risiko sisa setelah diterapkan pengendalian menunjukkan masih ada $24 \%$ risiko yang termasuk dalam kategori dapat ditolerir dan $76 \%$ risiko lainnya sudah dapat diteirma. Saran untuk perusahaan yaitu pekerja lebih disiplin menggunakan APD dan dilakukan pemasangan safety sign pada mesin yang berpotensi menimbulkan bahaya.

\section{DAFTAR PUSTAKA}

Baihaqi,Ramhat. 2014. 192.911 Peserta Jamsostek Alami Kecelakaan Kerja. http://ekbis.sindonews.com/read/836859/34/192-911peserta-jamsostek-alami-kecelakaan-kerja1392713047. Diakses 30 Maret 2015

Jumali, dkk. 2013. Prevalensi dan Faktor Risiko Tuli Akibat Bising pada Operator Mesin Kapal Feri. Jurnal Kesehatan Masyarakat Nasional Vol 7.No. 12: 545

Mahkamah Pelayaran. 2012. Jumlah Kecelakaan Kapal Berdasarkan Hasil Putusan Mahkamah Pelayaran. http://ppid.dephub.go.id/files/STATISTIK_PERHUBU NGAN_2012_BUKU_2.pdf. Sitasi 11 Agustus 2015.

Peraturan Menteri Tenaga Kerja Republik Indonesia Nomor 03/MEN/90/Tahun 1998 Tentang Tata Cara Pelaporan dan Pemeriksaan Kecelakaan
Peraturan Menteri Tenaga Kerja Republik Indonesia Nomor 05/MEN/1996 Tentang SMK3

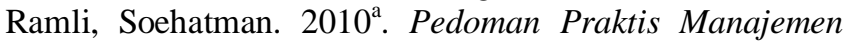
Risiko Dalam Perspektif K3 OHS Risk Management Jakarta: Dian Rakyat.

Ramli, Soehatman. 2010 ${ }^{\mathrm{b}}$. SMK3 OHSAS 18001. Jakarta : Dian Rakyat.

Raunek. 2013. 10 Extremely Dangerous Engine Room Accidents On Ships.

http://www.marineinsight.com/misc/marine-safety/10extremely-dangerous-engine-room-accidents/. Sitasi 8 Maret 2015.

Soetiono, Beny A. Pengaruh Safety Equipment Terhadap Keselamatan Berlayar. Jurnal Aplikasi Pelayaran dan Kepelabuhan Vol 1. No. 1: 75

Step Change In Safety. 2007. Task Risk Assessment Guide.

http://www.stepchangeinsafety.net/knowledgecentre/public ations/publication.cfm/publicationid/36

Wasimun. 2011. Apa Saja Yang Ada Di Dalam Kamar Mesin Kapal (Engine Room).

http://www.maritimeworld.web.id/2011/03/apa-saja-yangada-dalam-kamar-mesin.html. Sitasi 5 November 2014.

Tualeka, Abdul Rohim. 2013. Analisis Risiko. Surabaya. Graha Ilmu Mulia.

Zaky, Mochammad. 2014. Analisa Keselamatan Kapal Ferry Ro-Ro Ditinjau Dari Damage Stability. Jurnal Teknik BKI Vol 1: 15 